\title{
Women's mental health in times of COVID-19
}

Approximately nine months ago, the world population began to have negative experiences regarding to the spread of a respiratory virus, called severe acute respiratory syndrome coronavirus 2 (SARS-CoV-2). This virus is the etiological agent of COVID-19, a disease considered responsible for one of the worst outbreaks experienced by humanity. ${ }^{1}$ Not long ago, the COVID-19 pandemic affected the most diverse social strata in Brazil, which was the first country in Latin America with reported case. ${ }^{1}$

Due to the severe transmissibility, morbidity and mortality associated with the scarcity of knowledge about the pathogenesis of the virus and of the effective treatments, preventive measures and recommendations were installed to contain the spread of the disease. 2 The restriction of social coexistence, represented by social distancing, the mandatory use of masks and frequent hand washing, were some of the tools used, varying in intensity according to the health policies of each government. 1

In this context of social mitigation, feelings of fear and anguish resulting from the pandemic are afflicted and, connected to the yearning for a possible infection, becoming triggers for clinical manifestations of psychopathologies. ${ }^{3}$ On the other hand, among the impacts of the presence of psychic disorders is the impairment of quality of life, resulting from the reduction or complete loss of productivity in daily activities and/or in the maintenance of social relations. ${ }^{3}$ Thus, one can consider that mental disorders and social distancing have a twoway cause and effect relationship.

Recent research has shown a higher prevalence of symptoms for stress, anxiety and depression in the female population during the COVID-19 pandemic. Before the social distancing variable, female emotional vulnerability was both linked to hormonal changes during the pre-menstrual, pre and postpartum, and menopause periods, and to gender inequalities, which strengthen work overloads and violence against women. 3 Parallel to the consolidation of social restrictions, the rates of domestic, sexual, and unwanted pregnancy have increased 1 as a result of men spending longer time at home, which contributes to the significant prevalence of psychic clinical conditions in women during this period.

In addition, the following variables stand out as possible risk factors for the impairment of the female population's mental health during social isolation: being a young adult, residing in regions with high rates of cases and mortality of COVID-19, having a history of anxiety and depression, taking medication, reduced or absent of physical activity and leisure, and being unemployed.

In view of the significant impact of COVID-19, the world governments are prioritizing the consolidation of measures to control and combat this new disease and, despite the effectiveness of these resources, effects arising indirectly of the pandemic are being overshadowed, such as the impairment of mental health in the female population. Therefore, the necessity to create proactive strategies of a multi-professional nature, in order to cover and individualize the multiple factors that exert the influence on women's mental health.

Due to the profound absence or failure in the diagnosis and treatment for women affected by mental disorders and the high recurrence of these disorders in previous carriers, the need for specialized services that offer easy access care is highlighted. ${ }^{3}$ Teleconsultations with psychologists and psychiatrists is suggested to be expanded, however, alternative measures should be offered to patients who do not have access to digital resources. Therefore, we emphasize the need for investments also in the psychic management of this target public.

The crisis resulting from the new coronavirus pandemic has reflected, in addition to deficits in the health 
system, increased unemployment and wage cuts. It is known that economic instabilities are situations that predispose the emergence of mental disorders, ${ }^{4}$ which becomes relevant the implementation of strategies that mitigate these impacts, through online training courses for small entrepreneurs, strategies to help the existing ones, and labor measures that ensure women's employment.

Linked to this, the activities that improve the quality of life and prevent mental disorders, such as physical exercise and leisure activities, are less prevalent among women, due especially to the overload of functions associated with the double workday. 5 Thus, the new concepts linked to women's functionality suggest adjustments to the activities imposed within the family nuclei, such as the division of domestic roles among members, ${ }^{5}$ which would reduce the workload, facilitating leisure activities and physical exercises. Thus, either they are through programs and classes online or in person with physical educators, physiotherapists, occupational therapists and other trained professionals, provided that the restrictive measures are respected, it should be encouraged.

Due to the increased time devoted to studies, the absence of stable relationships and the formation of a late family nucleus, researchers have recognized the 18-29 age group as an important period of development and transition. ${ }^{6}$ This condition of life for young adults is associated with the socially imposed demands on women's function and the greater tendency to experience mood disorders, influencing the greater prevalence of psychopathologies among young women. 6 In view of this situation, special attention should be directed to this population, since they present a significant prevalence and recurrence, over a long period of time, of developing mental disorders, besides suicide.

Studies show that insomnia presents higher rates among women and increases as they get older. ${ }^{7}$ Although, there are uncertainties regarding to the causal relationship between sleeping and psychiatric disorders, it is believed that insomnia, besides being a typical symptom of psychopathologies, is also a predictor for depression and other mental illnesses. ${ }^{7}$ In view of the increasing frequency of non-diagnosis, sub-treatment, inadequate treatment and worsening of sleeping disorders during the COVID-19 pandemic, preventive and early recognition measures must be developed, such as the identification of precipitating factors and self-reported assessments. Cognitive-behavioral therapy is recommended as the treatment of first choice, which should be more available, since its beneficial effects, in contrast to those produced by medication, act in the long term. 8

As more information is obtained on the factors associated with women's mental health during the COVID19 pandemic, multidisciplinary strategies could be consolidated as guides for making better decisions on diagnoses, therapeutic conducts, and prevention of new cases. Attention should also be paid in the return of public policies on mental health, considering the "new normal" in the care of these women, to not prolong the diagnosis and the beginning of the treatment.

\section{References}

1. Senicato C, Azevedo RCS, Barros MBA. Transtorno mental comum em mulheres adultas: identificando os segmentos mais vulneráveis. CiêncSaúdeColetiva. 2018; 23: 2543-54.

2. Pessa VE, Cruz Vaz CDL, Luz LS, Silva Pereira MF, Lazzerini M. COVID-19 among health workers in Brazil: the silent wave. J Glob Health. 2020; 10: 010379.

3. Thapa SB, Mainali A, Schwank SE, Acharya G. Maternal mental health in the time of the COVID-19 pandemic. Acta ObstetGynecol Scand. 2020; 99: 817-8.

4. Mattos D. O impacto do desemprego e a saúde psicossocial. Psicologia.pt. 2018: 1-14. Disponível: https://www.psicologia.pt/artigos/textos/A1165.pdf

5. Pinho PS, Araújo TM. Associação entre sobrecarga doméstica e transtornos mentais comuns em mulheres. Rev Bras Epidemiol. 2012; $15: 560-72$.

6. Arnett JJ, Žukauskienė R, Sugimura K. The new life stage of emerging adulthood at ages 18-29 years: implications for mental health. Lancet Psychiatry. 2014; 1: 569-76. 
7. Salk RH, Hyde JS, Abramson LY. Gender differences in depression in representative national samples: Meta-analyses of diagnoses and symptoms. Psychol Bull. 2017; 143: 783-822.

8. Everitt H, Baldwin DS, Stuart B, Lipinska G, Mayers A, Malizia AL, Manson CC, Wilson S. Antidepressants for insomnia in adults. Cochrane Database Syst Rev. 2018; 5:CD010753.

Alex Sandro Rolland Souza 1

(iD) https://orcid.org/0000-0001-7039-2052

Gustavo Fonseca de Albuquerque Souza 2

iD https://orcid.org/0000-0002-1794-701X

Gabriella de Almeida Figueredo Praciano 3

iD https://orcid.org/0000-0002-9746-8536

${ }^{1}$ Instituto de Medicina Integral Prof. Fernando Figueira. Rua dos Coelhos, 300. Boa Vista. Recife, PE, Brasil. CEP: 50.070-550.

2,3 Universidade Católica de Pernambuco. Rua do Príncipe, 526. Boa Vista. Recife, PE, Brasil. CEP: 50.050-900. 